\title{
The Role of Atypical Antipsychotic Therapy for Patients with Treatment- Resistant Bipolar Depression
}

\author{
Anish S Shah* \\ 1260 N Dutton Ave, Suite 275, Santa Rosa, CA, 95401, USA
}

*Corresponding author: Anish S. Shah, 1260 N Dutton Ave, Suite 275, Santa Rosa, Ca, 95401, USA, Tel: 7076968045; E-mail: ashah@siyanclinical.com

Received Date: August 29, 2014, Accepted Date: September 23, 2014, Published Date: September 30, 2014

Copyright: (c) 2014, Anish S. Shah et al., This is an open-access article distributed under the terms of the Creative Commons Attribution License, which permits unrestricted use, distribution, and reproduction in any medium, provided the original author and source are credited.

\begin{abstract}
Physicians treating patients with bipolar depression have a unique challenge when considering drug therapy. Historically, patients with bipolar depression have been treated with SSRIs or other medications commonly utilized with patients presenting with non-bipolar depression. Indeed, many of these medications are not ideal for patients suffering from bipolar depression. Recently, a class of second-generation atypical antipsychotics has emerged as an exciting new avenue for the treatment of bipolar depressive episodes. While these medications have received a wealth of empirical support for treating treatment-resistant unipolar depression, less is known about the efficacy of these medications in treating bipolar depression. Early evidence is promising, though additional trials may be warranted to more clearly delineate the role of second-generation atypical antipsychotics in treating bipolar depressive episodes. This article discusses the second-generation atypical antipsychotics that have received empirical support for use in treating depressive symptoms in patients with bipolar depression. Current FDA approvals for usage are reviewed and avenues for future work are proposed.
\end{abstract}

Keywords: Bipolar depression; Treatment-resistant; Depression; Second-generation antipsychotics; Atypical antipsychotic therapy; Depression treatment

\section{Introduction}

The annual prevalence estimates for bipolar disorder around the world range from $0.0 \%$ in some countries to $0.6 \%$, and are around $0.3 \%$ for bipolar II disorder [1]. For both bipolar disorders, the mean age of onset for the first major depressive episode is between approximately 18 to 20 years old, with bipolar II having a slightly later onset. Suicide risk is particularly important among individuals with bipolar disorder. In fact, some estimates have suggested that the risk for suicide among individuals with bipolar disorder is more than 15 times more than that of the general population [2]. Moreover, bipolar disorder is associated with significant functional impairments. Approximately $30 \%$ of individuals with bipolar disorder exhibit significant impairment at work [3]. Individuals with bipolar disorder are more likely to fall in the lower socioeconomic classes, perform worse on tests of cognitive abilities, and endure interpersonal difficulties [3-5]. While acute manic episodes associated with bipolar disorder have the potential to be dangerous, patients with bipolar disorder also tend to suffer more from episodes of depression for longer periods of time [6,7]. Thus, it is believed that it is actually the depressive episodes associated with bipolar disorder that account for the individual's persistent functional impairment [8]. Indeed, findings from previous studies have suggested that individuals recently diagnosed with bipolar disorder spend approximately three times more time in a depressive episode compared to both mania and hypomania [9]. Further, depressive episodes associated with bipolar disorder carry with the man augmented risk for relapse into mania, along with poorer prognoses for the patient [9].
Individuals with bipolar depression present unique challenges for their treating physicians. In fact, depression that is induced by bipolar disorder is regarded as more refractory than unipolar depression and is characterized by a less favorable treatment response [7]. Traditionally, in the US, individuals with depression that has been induced by bipolar disorder are treated with mediations that are known to be effective for individuals suffering from unipolar depression; however, controversy exists. Indeed, as a general principal, Canadian physicians are encouraged to discontinue antidepressants with their patients who have bipolar depressive episodes [9]. These medications, traditionally used for unipolar depression, include selective serotonin reuptake inhibitors (SSRIs), serotoninnorepinephrine reuptake inhibitors (SNRIs), and bupropion. Indeed, a meta-analysis, which considered evidence from twelve randomized, controlled trials, found some support for the efficacy of antidepressants as a short-term management option for bipolar depression [9]. However, physicians considering these medications to treat depressive episodes among their patients with bipolar disorder have done so with particular caution, as these medications have been shown to precipitate accelerated mood switching to mania or even activate rapid cycling [10,11]. This risk appears to be particularly relevant for the use of SNRIs. Evidence from clinical trials using these medications have indicated that a generous portion of bipolar disorder patients can expect a degree of improvement in their depressive symptoms from these treatments when compared to a placebocontrolled group (i.e., approximately $45 \%$ achieved remission status) [13].

Nonetheless, concerns with regard to the divide between statistically significant and subjectively significant improvements still exist. More specifically, patients are considered treatment "responders" simply by achieving a 50\% improvement in depressive symptoms according to a standardized rating scale. While this, indeed, characterizes a statistically significant improvement in symptom presentation in 
terms of the rating scale, a portion of these patients may continue to suffer from clinically concerning symptoms. Further, some patients may even continue to exhibit functional impairments from the refractory symptoms of depression. This subset of patients characterized by treatment-resistant bipolar depression warranted a search for alternative treatment options, which led to the use of antipsychotics. Currently, several drugs have received FDA approval for the maintenance of bipolar disorder, including mood stabilizers, such as lamotrigine and lithium, and atypical antipsychotics, such as olanzapine, aripiprazole, and risperidone. However, this subclass of antipsychotics, in particular, has been shown to lengthen the time between episodes of depressive symptoms [11]. These medications have been particularly promising in trials on adults who present with extensive histories of drug trials for treating their bipolar depressive episodes. Indeed, there is currently more support for the use of atypical antipsychotics among populations of unipolar depression; however, several recent trials have suggested that the augmentation of atypical antipsychotics may be equally effective for treating bipolar depression [14-23].

Clinical trials regarding atypical antipsychotic therapy for bipolar depression were thoroughly reviewed for the purpose of this article. The literature search focused on FDA-approved, second generation antipsychotics for bipolar disorder and bipolar depression. Accordingly, this article provides a discussion of the use of secondgeneration, atypical antipsychotics as an augmentation treatment for patients with bipolar depression, particularly those with refractory depressive symptoms.

\section{FDA Approval of Second-Generation Antipsychotics}

Olanzapine has received FDA approval for treating schizophrenia in adults and adolescents, bipolar I disorderin adults and adolescents (mixed or manic bipolar episodes), in combination with fluoxetine for the treatment of bipolar I depression in adults, children, and adolescents, and for treatment-resistant depression in adults [24,25]. Several previous studies have documented olanzapine as beneficial for treating patients with treatment-resistant depression [24-28].

Quetiapine has received FDA approval for treating schizophrenia in adults and adolescents aged 13 to 17, bipolar mania in adults, children, and adolescents aged 10-17 years, bipolar depression, and for bipolar maintenance [29-31]. Further, the immediate release form of quetiapine (i.e., quetiapine IR) has not received FDA approval for the treatment of depression; however, the extended release form (i.e., quetiapine $\mathrm{XR}$ ) is supported by the FDA as an adjunctive treatment for major depressive disorder. Existing work has supported quetiapine as an augment agent in the treatment of treatment-resistant depression [29-31]. Additionally, a recently-conducted study examined the pooled data of four placebo-controlled trials on the use of quetiapine for the treatment of bipolar II depression. This study found that quetiapine was associated with higher rates of remission and greater improvements in patient-reported depressive symptoms when compared to placebo [31].

Aripiprazole has received FDA approval for treating schizophrenia in adults and adolescents, bipolar disorder (both manic and mixed episodes), bipolar mania in adults, children, and adolescents, bipolar I maintenance, and major depressive disorder [32,33]. Several studies exist, which have documented the beneficial effects of using aripiprazole as an augment medication for treating patients with treatment-resistant depression $[32,33]$. In terms of bipolar depression, results are somewhat mixed. Indeed, several studies have found that while aripiprazole was associated with improvements in patientreported symptoms of depression in the early phases of treatment; however, when symptom improvement was compared after 8 weeks, aripiprazole did not significantly differ from placebo [33]. Furthermore, while aripiprazole has been supported as effective in delaying the relapse of manic episodes in patients with bipolar disorder, little evidence exists for its use in delaying the onset of depressive episodes. Findings from current research have shown that relapse rates for bipolar depression are similar for aripiprazole and placebo [33]. Indeed, the data remain mixed for the efficacy of aripiprazole in treating bipolar depression, which may be due to a number of study limitations, including rapid titration and the use of high dosages. More work is necessary to examine the role of aripiprazole in treating bipolar disorder.

Risperidone has received FDA approval for treating schizophrenia in adults and adolescents, bipolar disorder (both manic and mixed episodes), bipolar mania in adults, child, and adolescents, major depressive disorder, and treatment-refractory depressive disorder [34-37]. Findings from previous studies have supported the use of risperidone in the treatment of unipolar depression, particularly in instances where the patient has not responded to SSRIs alone [36-38]. Few recent studies exist examining the efficacy of risperidone in the treatment of bipolar depression and the findings from these studies remain mixed. While some data has shown that risperidone is associated with improvements in patient-reported symptoms of bipolar depression [34], other findings have suggested that these improvements do not significantly differ from placebo [35]. Indeed, more data is necessary to examine the use of risperidone in treating bipolar depression.

Ziprasidone has received FDA approval for treating schizophrenia in adults, bipolar I disorder in adults (both manic and mixed episodes), and maintenance of bipolar I disorder in adults [39,40]. Findings from previous studies have supported the use of ziprasidone in the treatment of unipolar depression, particularly in instances where the patient has not responded to SSRIs alone [39]. Very little data exists on the use of ziprasidone in treating bipolar depression. While some evidence exists on the benefits of ziprasidone in reducing patient-reported symptoms of bipolar depression, these findings have not been compared to placebo [40]. Thus, future work is necessary to compare the reduction in depressive symptoms among patients with bipolar disorder across trials of ziprasidone and placebo. Further, studies are also necessary to examine the long-term benefits of ziprasidone in preventing the relapse of depressive episodes among patients with bipolar disorder.

Two recently developed antipsychotics (asenapine and Lurasidone) have received FDA approval for the treatment of schizophrenia and bipolar disorder [41,42]. Findings from clinical trials have supported Lurasidone's efficacy in treating bipolar depression as both a monotherapy, as well as an adjunctive therapy, and these benefits have been found to be superior to placebo [41,42]. Outcomes from clinical trials specifically examining the efficacy of asenapine on the treatment of depression associated with bipolar disorder have not yet been published.

\section{Conclusion and Future Directions}

Bipolar depression is of particular concern when considering drug therapy, as there is some risk for inducing mania or rapid cycling. 
Thus, traditional medications utilized with major depression are not ideal for use with patients suffering from bipolar disorder. Recently, a class of atypical antipsychotics has emerged as an exciting new avenue for the treatment of depressive episodes in bipolar disorder. While these medications have received a wealth of empirical support for treating treatment-resistant unipolar depression, very little is known as to whether these drugs are equally as successful in treating bipolar depression. Indeed, findings remain mixed for several of these drugs in terms of their superiority above a placebo in effectively reducing symptoms of bipolar depression and in preventing relapse of a mood episode [43]. Thus, more work on the role of atypical antipsychotics in the treatment of bipolar depressive episodes is necessary. For instance, direct comparisons between these atypical antipsychotic medications have not been conducted in order to identify whether one drug is more effective than another. Further, the role these medications play in preventing/inducing future manic episodes or in mitigating the deleterious impacts bipolar depressive episodes have on the patient's functioning remains to be uncovered. More work is also necessary on the role of antipsychotics in treating treatment-resistant bipolar depression. For instance, the underlying mechanisms that account for their superior effectiveness over typical treatment choices for depression still is not fully understood. It will also be important for these studies to establish an optimal length of time for treatment with antipsychotics. In other words, determine whether patients with bipolar disorder need to remain on a steady dosage to prevent future depressive episodes. And finally, the long-term risk for tardive dyskinesia has yet to be established. Findings from these studies can begin to delineate the role that these drugs can play in alleviating debilitating symptoms of depression that characterize bipolar impairment and improve the patient's quality of life.

\section{References}

1. American Psychiatric Association (2013) Diagnostic and statistical manual of mental disorders (5th ed.) Washington, DC: Author.

2. Pawlak J, Dmitrzak-Węglarz M, Skibińska M, Szczepankiewicz A, Leszczyńska-Rodziewicz A, et al. (2013) Suicide attempts and clinical risk factors in patients with bipolar and unipolar affective disorders. Gen Hosp Psychiatry 35: 427-432.

3. Proudfoot J, Whitton A, Parker G, Manicavasagar V, Nicholas J, et al. (2014) Evidence of weekly cyclicity in mood and functional impairment in those with a bipolar disorder. Psychiatry Res 218: 290-294.

4. Aprahamian I, Ladeira R, Diniz B, Forlenza O, Nunes P (2014) Cognitive impairment in euthymic older adults with bipolar disorder: A controlled study using cognitive screening tests. Am J Ger Psychiatry 22: 389-397.

5. Vöhringer P, Barroilhet S, Amerio A, Reale ML, Alvear K, et al. (2013) Cognitive impairment in bipolar disorder and schizophrenia: A systematic review. Frontiers In Psychiatry 4: 1-11.

6. Hlastala SA, Frank E, Mallinger AG, Thase ME, Ritenour AM, et al. (1997) Bipolar depression: An underestimated treatment challenge. Depress Anxiety 5: 73-83.

7. Kupfer DJ, Frank E, Grochocinski VJ, Luther JF, Houck PR, et al. (2000) Stabilization in the treatment of mania, depression, and mixed states. Acta Neuropsychiatr 12: 3-114.

8. Altshuler LL, Gitlin MJ, Mintz J, Leight KL, Frye MA (2002) Subsyndromal depression is associated with functional impairment in patients with bipolar disorder. J Clin Psychiatry 63: 807-811.

9. Grunze H, Vieta E, Goodwin GM, Bowden C, Licht RW, et al. (2010) The World Federation of Societies of Biological Psychiatry (WFSBP) Guidelines for the Biological Treatment of Bipolar Disorders: Update 2010 on the treatment of acute bipolar depression. Wor J Biol Psychiatry 11: 81-109.
10. Gijsman HJ, Geddes JR, Rendell JM, Nolen WA, Goodwin GM (2004) Antidepressants for bipolar depression: A systematic review of randomized, controlled trials. Am J Psychiatry 161: 1537-1547.

11. American Psychiatric Association (2002) Practice guideline for the treatment of patients with bipolar disorder [Revision]. Am J Psychiatry 159: 1-50.

12. Leverich GS, Altshuler LL, Frye MA, Suppes T, McElroy SL, et al. (2006) Risk of switch in mood polarity to hypomania or mania in patients with bipolar depression during acute and continuation trials of venlafaxine, sertraline, and bupropion as adjuncts to mood stabilizers. Am J Psychiatry 163: 232-239.

13. Thase ME, Entsuah AR, Rudolph RL (2001) Remission rates during treatment with venlafaxine or selective serotonin reuptake inhibitors. Br J Psychiatry 178: 234-241.

14. Yatham LN, Goldstein JM, Vieta E, Bowden CL, Grunze H, et al. (2005) A typical antipsychotics in bipolar depression: Potential mechanisms of action. J Clin Psychiatry 66: 40-48.

15. Nemeroff CB (2005) Use of atypical antipsychotics in refractory depression and anxiety. J Clin Psychiatry 66: 13-21.

16. Thase ME (2002) What role do atypical antipsychotic drugs have in treatment-resistant depression? J Clin Psychiatry 63: 95-103.

17. Shelton RC, Papakostas GI (2008) Augmentation of antidepressants with atypical antipsychotics for treatment-resistant major depressive disorder. Acta Psychiatry Scand 117: 253-259.

18. Shelton RC, Tollefson GD, Tohen M, Stahl S, Gannon KS, et al. (2001) A novel augmentation strategy for treating resistant major depression. Am J Psychiatry 158: 131-134.

19. Fawcett J (1994) Progress in treatment-resistant and treatment-refractory depression: We still have a long way to go. J Clin Psychiatry 24: 214-216.

20. Patkar AA, Pae CU (2013) Atypical antipsychotic augmentation strategies in the context of guideline-based care for the treatment of major depressive disorder. CNS Drugs 27: S29-S37.

21. Spielmans GI, Berman MI, Linardatos E, Rosenlicht N, Perry A, et al. (2013) Adjuctive atypical antipsychotic treatment for major depressive disorder: A meta-analysis of depression, quality of life, and safety outcomes. PLoS Med 10: e1001403.

22. Nelson JC, Papakostas GI (2009) Atypical antipsychotic augmentation in Major Depressive Disorder: A meta-analysis of placebo-controlled randomized trials. Am J Psychiatry 166: 980-991.

23. Selle V, Schalkwijk S, Vázquez GH, Baldessarini RJ (2014) Treatments for acute bipolar depression: Meta-analyses of placebo-controlled, monotherapy trials of anticonvulsants, lithium, and antipsychotics. Pharmacopsychiatry 47: 43-52.

24. Bymaster FP, Nelson DL, DeLapp NW, Falcone JF, Eckols K, et al. (1999) Antagonism by olanzapine of dopamine D1, serotonin1, muscarinic, histamine $\mathrm{H} 1$, and alpha 1-adrenergic receptors in vitro. Schizophr Res 37: 107-122.

25. Corya SA, Williamson DJ, Sanger TM, Briggs SD, Case M, et al. (2006) A randomized, double-blind comparison of olanzapine/fluoxetine combination, olanzapine, fluoxetine, and venlafaxine in treatmentresistant depression. Depress Anxiety 23: 364-372.

26. Tohen M, Vieta E, Calabrese J, Ketter TA, Sachs G, et al. (2003) Efficacy of olanzapine and olanzapine-fluoxetine combination in the treatment of bipolar I depression. Arch Gen Psychiatry 60: 1079-1088.

27. Thase M, Corya SA, Osuntokun O, Case M, Henley DB, et al. (2007) A randomized, double-blind comparison of olanzapine/fluoxetine combination, olanzapine, and fluoxetine in treatment-resistant major depressive disorder. J Clin Psychiatry 68: 224-236.

28. Shelton RC, Williamson DJ, Corya SA, Sanger TM, Van Campen LE, et al. (2005) Olanzapine/fluoxetine combination for treatment-resistant depression: A controlled study of SSRI and nortriptyline resistance. J Clin Psychiatry 66: 1289-1297.

29. Mc Elroy SL, Weisler RH, Chang W, Olausson B, Paulsson B, et al. (2010) A double-blind, placebo-controlled study of quetiapine and paroxetine as 
Citation: Shah SA (2014) The Role of Atypical Antipsychotic Therapy for Patients with Treatment-Resistant Bipolar Depression. J

monotherapy in adults with bipolar depression (EMBOLDEN II). J Clin Psychiatry 71: 163-174.

30. Calabrese JR, Keck PE, MacFadden W, Minkwitz M, Ketter TA, et al. (2005) A randomized, double-blind, placebo-controlled trial of quetiapine in the treatment of bipolar I or II depression. Am J Psychiatry 162: 1351-1360.

31. Young AH, Calabrese JR, Gustafsson U, Berk M, McElroy SL, et al. (2013) Quetiapine monotherapy in bipolar II depression: Combined data from four large, randomized studies. Int J Bipolar Disord 10: 1-12.

32. Pae CU, Forbes A, Patkar AA (2011) Aripiprazole as adjunctive therapy for patients with major depressive disorder: Overview and implications of clinical trial data. CNS Drugs 25: 109-127.

33. Yatham LN (2011) A clinical review of aripiprazole in bipolar depression and maintenance therapy of bipolar disorder. J Affect Disord 128: S21S28.

34. Vieta E, Goikolea JM, Corbella B, Benabarre A, Reinares M, et al. (2001) Risperidone safety and efficacy in the treatment of bipolar and schizoaffective disorders: Results from a 6-month, multicenter, open study. J Clin Psychiatry 62: 818-825.

35. Shelton RC, Stahl SM (2004) Risperidone and paroxetine given singly and in combination for bipolar depression. J Clin Psychiatry 65 1715-1719.

36. Reeves H, Batra S, May RS, Zhang R, Dahl DC, et al. (2008) Efficacy of risperidone augmentation to antidepressant in the management of suicidality in major depressive disorder: A randomized, double-blind, placebo controlled pilot study. J Clin Psychiatry 69: 1228-1336.
37. Mahmoud RA, Pandia G, Turkoz I, Kosik-Gonzalez C, Canuso CM, et al. (2007) Risperidone for treatment-refractory depressive disorder: A randomized trial. Ann Intern Med 147: 593-602.

38. Keitner GI, Garlow SJ, Ryan CE, Ninan PT, Solomon DA, et al. (2009) A randomized, placebo-controlled trial of risperidone augmentation for patients with difficult-to-treat unipolar, non-psychotic major depression. J Psychiatry Res 43: 205-214.

39. Sachs GS, Ice KS, Chappell PB, Schwartz JH, Gurtovaya O, et al. (2011) Efficacy and safety of adjunctive oral ziprasidone for acute treatment of depression in patients with bipolar I disorder: A randomized, doubleblind, placebo-controlled trial. J Clin Psychiatry 72: 1413-1422.

40. Liebowitz MR, Salmán E, Mech A, Dunner D, Johnson AE, et al. (2009) Ziprasidone monotherapy in bipolar II depression: An open trial. J Affect Disord 118: 1-3.

41. Loebel A, Cucchiaro J, Silva R, Kroger H, Hsu J, et al. (2014) Lurasidone monotherapy in the treatment of bipolar I depression: A randomized, double-blind, placebo-controlled study. Am J Psychiatry 171: 160-168.

42. Loebel A, Cucchiaro J, Silva R, Kroger H, Sarma K, et al. (2014) Lurasidone as adjunctive therapy with lithium or valproate for the treatment of bipolar I depression: A randomized, double-blind, placebocontrolled study. Am J Psychiatry 171: 169-177.

43. Cruz N, Sanchez-Moreno J, Torres F, Goikolea JM, Valentí M, et al. (2010) Efficacy of modern antipsychotics in placebo-controlled trials in bipolar depression: A meta-analysis. Int J Neuropsychopharmacol 13: 5-14. 